EVIDENCE IN METEORITUS FOR AN ACTIVE EARLY SUN: M. W. Cafiee", J. N. Goswaml ${ }^{2}$, C. M. Hohenberg'. T. D. Swindle'. (1) Mclonnell Center for the Space Sriences ard Dept. of Physics, Washingion Univ., St. Louls, MO. 63130. (2) Physical Research Laboratory, Ahmedabad-380009. India.

Was the sun once brigiter than it is trilay? Recent meteorlte studles suggest that the sun may have gone through a pertod of latense solar fare actlvity as a young star 1.5 billion years ago. Astronomical observations of a class of stars called $T$-Taurt stars, stars that are similar In size tc our sun but In a much younger stage of evoiution (severa' million years old or lers), show that this class of stara can be very active. Sclentists have suspected that our sun also went through a period of Increased activity, but it's difficult to find direct evidence for an event that happened so long ago.

However, In the same way that spacecraft are sent to other planets to gather new information, meteorites can serve as probes into our solar system's early activity. Most meteorites lormed about 4.5 billion yaars ago, and have been altered little since then. Some of these meteorites contain grains that were individually exposed to energetic particles before formation of the meteorite. The. grains heye preserved a record of the early solar activity that can be studied. We have found that these grains have surprisingly large abundances of a rare lsotope of neon. whirh can only be produced by energetic particles. These particles can come from only two sources: galactlc cosmic rays or sola: flares Unless the grains were exposed to galactic cosmic rays for a much longer pertod than is predicted by current theortes, this excess neon must have been produced by solar flares at least 100 times more intense than those of our present sun.

A simple history for this type of meteorite includes three stages. In the first stage, which ociurred at leas: 3.5 billion years ago (more likely 4.5 billion years ago), some mineral grains were exmand in iitt sun, while others, deeper In clumps or within the rubbled surfare s: a small asteroid-like body, were not. In the next stage, many grains, oniy a few of which had been exposed to the sun, were compacted together in a solid object, shiclded from further bo.nbaidment by energetic particles. ihis stage constiiutes the major period of a meteorite's history. Finally, sometime within the last 30 million years or so, this larger body broke apart. probably the result of collisions tha' a'so placed the meteorite on a collision colrse with the earth. 


\section{EVIDENCE IN METEORITES}

$$
\text { Caffee, } \mathrm{M} \text {. W. et al. }
$$

We can learn about these three stages of exproun from the records the gralns have ritalned. For example, if we treat the grains with acid and look at Individual grains under a microscope, we find that some grains ( 5 to 10 percent of the grains in the meteorties we've studled) show evidence of exposuie to solar flares. During a solar flare, the sun ejects particies at a high enough energy that they will penetrate the first $10-20$ mlcrons (milliontlas of a meter) of a nuck, leaving a scar in the rock that the acid attacks and enlarges to make a visible "track." Since these solar flares are stopped In such a short distance, grains with solar flare traiks must have been exyosed directly to the sun. Furthernore, those grains must have been exposed to the sun In the first stage of their hlstory, since they were recovered from inside the meteorite.

Meteorites are also bombarded by galzctlc -osmic rays. The galactic cosmic rays, which do not come from our solar system, are mostly protons that are moving at nearly the speed of light. They have energies comparable to those produced by the most powerful particle accelerators on earth. These cosmic rays can petetrate only a few meters of soll or rock. so grains in meteorites can be exposed w them during the early and recent stages of their history, but not during the long intermediate stage of deep burial. When a cosmic ray procon collides with an atomic nucleus within a rock, it can break off ("spall") part of the nurleus, converting it into a different elerient. We study neon, which can be produced from common elements like magnesium or ailicon in this type of reaction. One particular isotope of neon, neon-21. is rare in meleorites unless such spallation reactions have occurred. Solar flare particles can also produce spallation reactlons, but in the modern solas system, the number and intensity of solar flares are low enuugh that the products of such reactions are rare and difficult to detect. However, this might not have been true of the early solar system.

In our experiment, we compared the amounts of neon-21 produced by spailation reactions in grains that had been exposed to the sun (in other words. grains that had solar flare tracks) and grains that had not. Since all the grains had the same exposure in all but the earllest stage of the history of the meteorite, we hoped to find out something about that eariiest stage. In three different meteorites, grains that had been exposed to solar flares had much more neon-21 (by factors as large as 50) than those that had not. If the neon-21 wre prcduced by galactic cosmic rays, these grains must have had early exposures of 


$$
\text { Caffee, M. h. et al. }
$$

up to several bundred million years, much longer than models of meteurite evolution predict. On the other hand. If solar hares were much more numerous and much more energetic when the sun was joung. those tares could have produced the effects we see in a much shorter tine span. For instance. solar activity 100 times greacer than current a ' ir activity would require piecompaction exposure uines of only a few million years. These times would then agree with moat models for meteorite formation.

There are questions remalning to be answered before accepting th's evidence as proof that the cariy sun was more active. For example, we need wo know precisely when the carly producticn of neun-21 took place. This is important since the period of enhanced solar llare activity would not be experted to last more than several million years. Therefore, If any of the grains containing the excess neon-2t are murlt younger than 4.5 bllion years old (for example. If they are only 3.5 billion years old). a dificrent explanation would have to be found. There are currently experiments under way that we hope will answer thrse questions. 